\title{
Year in review and appreciation for 2020 reviewers
}

\section{Sue Kim}

College of Nursing, Yonsei University, Seoul, Korea

What a year it has been, which started as the Year of the Nurse and the Midwife, designated by the World Health Organization, but was swiftly consumed by the coronavirus disease 2019 (COVID-19) pandemic world-wide. Looking back on the Korean Journal of Women Health Nursing (KJWHN), we had a dynamic year as well, which I hope to summarize in this editorial, while sharing plans for the upcoming year.

\section{Year in review and preparing for 2021}

This year KJWHN transitioned to a greater number of review articles and an increase in manuscripts available in English. Out of the total number of original manuscripts this year we have published six review papers (including four in this issue), and will continue to welcome integrative reviews, scoping reviews, and systematic reviews and/or meta-analyses that fit our aims and scope. As for increasing English manuscripts in 2020, 13 out of 38 published papers (34.2\%; 32 unsolicited, six commissioned manuscripts) and seven out of 32 unsolicited articles (21.9\%) were published in English, which will no doubt promote visibility of the important contributions of our authors. KJWHN seeks to steadily increase the proportion of English manuscripts for the benefit of our readers, especially those that offer an international perspective.

This year KJWHN published rich topics in our Issues and Perspectives section, starting with the push for nurses to become more familiar with artificial intelligence (AI) in research, education, and practice [1]. COVID-19 has brought limitations in both in-class teaching and clinical practicum, especially for women's health nursing education. It has also heightened the importance of big data and digital competency. As such, we hope to see more research on how nurses have used digital technology in teaching and are exploring $\mathrm{AI}$ application in research and practice.

Another issue paper analyzed the impact of COVID-19 on women and underscored the need for a gendered perspective of data collection in Korea [2]. Since then, an analysis of published COVID-19 research papers have shown that women's authorship is disproportionately low [3]. Also a study on work status following COVID-19 in Gyeonggido province, Korea, reported how women's work is being negatively affected while their caregiving burden is increasing [4]. Although gender inequalities in health care is not a new issue, it has certainly emerged with greater importance since COVID-19 [5] and will no doubt challenge us to approach the multiple issues relevant for women with the ongoing pandemic. KJWHN invites commentaries or original manuscripts specifically on COVID-19 impact on women's health.

In response to our third issue paper's challenge to nurses and midwives to share their stories as a
Received: December 19, 2020

Accepted: December 28, 2020

Corresponding author:

Sue Kim

College of Nursing, Yonsei

University, 50-1 Yonsei-ro,

Seodaemun-gu, Seoul 03722, Korea

Tel: +82-2228-3276

E-mail:suekim@yuhs.ac

This is an Open Access article distributed under the terms of the Creative Commons Attribution License (http://creativecommons.org/licenses/by/4.0) which permits unrestricted use, distribution, and reproduction in any medium, provided the original work is properly cited.

Copyright (c) 2020 Korean Society of Women Health Nursing 
way to inform the public and promote our profession [6], the Korean Society of Women Health Nursing sent out a call for creative submissions related to nursing and women's health. Readers can find the essay that won first prize in this issue of KJWHN, and other selected works are posted on the society's webpage (https://women-health-nursing.or.kr/).

Our last issue paper (December issue) presents a call to action for strengthening midwives as a strategy to alleviate the ultra-low birth rate in Korea. The challenge of Korea's low birth rate demands serious attention and the Presidential Committee on Ageing Society and Population Policy (PCASPP) has announced the Fourth Framework Plans for Korea on December 15,2020 , which will be the road map for the period 2021 to 2025 [7]. This Framework Plan does not specifically note the potential role of midwives and KJWHN intends to follow up on these developments in 2021, with a paper from PCASPP members and/or key experts.

On another note, author guidelines have been updated as of the December 2020 issue for manuscript length (English manuscripts within 5,000 words, excluding tables, figures, and references) and removing the restriction of overall number of references (although supportive citations in the text should be two or less per argument). These changes have been made to reflect international trends and are available online.

\section{Appreciation for 2020 reviewers}

I am indebted to our reviewers, not to mention our tireless editors and editorial board members, for their commitment and support for KJWHN.

\author{
Ahn, Suk Hee (Chungnam National University) \\ Bae, Kyung Eui (Dongseo University) \\ Chae, Hyun Ju (Joongbu University) \\ Chae, Myung-Ock (Cheongju University) \\ Cheon, Suk Hee (Sangji University) \\ Cho, In Sook (Inha University) \\ Cho, Ok Hee (Kongju National University) \\ Choi, Mi Young (National Evidence-based Healthcare Collabo- \\ ration Agency) \\ Choi, So Young (Gyeongsang National University) \\ Chung, Chae Weon (Seoul National University) \\ Drake, Emily E. (University of Virginia) \\ $\mathrm{Ha}$, Ju Young (Pusan National University) \\ Han, Yong Hee (Hallym Polytechnic University) \\ Hong, Se Hoon (CHA University) \\ Hwang, Kyung Hye (Suwon Science College)
}

Hwang, Moon Sook (Woosuk University)

Jeong, Geum Hee (Hallym University)

Chung, Mi Young (SunMoon University)

Go, Gee Youn (Dongguk University)

Jo, Myung Ju (The Catholic University of Korea)

Kang, Hee Sun (Chung-Ang University)

Kang, Sook Jung (Ewha Womans University)

Kim, Bo Yeoul (Eulji University)

Kim, Hee Kyung (Kongju National University)

Kim, Hee Sook (Dongnam Health University)

Kim, Hyun Kyoung (Kongju National University)

Kim, Jeung Im (Soonchunhyang University)

Kim, Mi Ok (Dankook University)

Kim, Ju Hee (Kyunghee University)

Kim, Kyung Won (Daegue Hanny University)

Kim, Mi Jong (Hannam University)

Kim, Mi Young (Woosuk University)

Kim, Moon Jeong (Pukyung National University)

Kim, Myoung hee (Semyung University)

Kim, Su Hyun (Nambu University)

Kim, Sun Hee (Daegu Catholic University)

Kim, Young Ju (Daegu Health Institute of Technology)

Kim, Yun Mi (Eulji University)

Ko, Eun (Sunchon National University)

Lee, Nae Young (Silla University)

Lee, Kyoung-Eun (Texas A \& M University)

Moon, So Hyun (Chosun University)

Nho, Ju Hee (Jeonbuk National University)

Park, Hyun Jung (Pyeongtaek University)

Park, Hye Sook (Dongyang University)

Park, Mi Kyung (Nambu University)

Park, Mee Ra (Changshin University)

Park, Seo A (Gyeongbuk College of Health)

Park, So Mi (Yonsei University)

Shin, Gi Soo (Chung-Ang University)

Son, Hae Kyoung (Eulji University)

Song, Ju Eun (Ajou University)

Sung, Mi Hae (Inje University)

Yeo, Jung Hee (Dong-A University)

Yeom, Gye Jeong (JEI University, Incheon)

Yoon, Ji Won (Shinhan University)

\section{Journal statistics}

Data on manuscripts submitted to KJWHN this year, as of December 19, 2020, are presented in Table 1. While there have been reports of manuscript submissions fluctuating and review 
Table 1. Basic statistics on manuscripts submitted to the Korean Journal of Women Health Nursing in 2020

\begin{tabular}{|c|c|c|}
\hline Category & Data & Notes \\
\hline Commissioned manuscripts ( $\mathrm{n}$ ) & 6 & 2 Editorials, 4 Issues \& Perspectives \\
\hline Unsolicited manuscripts ( $\mathrm{n}$ ) & 47 & \\
\hline Accepted manuscripts ( $\mathrm{n}$ ) & 32 & \\
\hline Non-accepted manuscripts ( $n$ ) & 13 & 11 Rejected, 2 withdrawn \\
\hline Manuscripts reviewed and determined (n) & 43 & 32 Accepted and published, 11 rejected \\
\hline Manuscripts under review or revision (n) & 2 & Under revision \\
\hline Acceptance rate (\%) & 71.1 & $32 / 45=0.711$ \\
\hline Average time from submission to acceptance (days) & 51.37 & \\
\hline
\end{tabular}

processes taking longer with the ongoing COVID-19 [8], KJWHN is fortunate to have had a steady flow of submissions and we thank our authors and society members for their dedication to research and dissemination.

\section{Upcoming developments}

In $2021 \mathrm{KJWHN}$ will offer a series of methods papers on instrument development and validity and reliability, and statistical reports relevant to women's health in Korea, as collaborative work with Statistics Korea. As noted above, KJWHN will also continue to follow the issues on the ultra-low birth rate in Korea. We hope you will stay tuned for these developments and consider becoming an active part of the dialogue by submitting your scholarly works for publication.

\section{ORCID}

Sue Kim, https://orcid.org/0000-0003-3785-2445

\section{Authors' contributions}

All work was done by Kim S.

\section{Conflict of interest}

Sue Kim has been editor-in-chief of the Korean Journal of Women Health Nursing since January 2020. She was not involved in the review process of this editorial. Otherwise, there was no conflict of interest.

\section{Funding}

None.

\section{Data availability}

Please contact the corresponding author for data availability.

\section{Acknowledgments}

None.

\section{References}

1. Jeong GH. Artificial intelligence, machine learning, and deep learning in women's health nursing. Korean J Women Health Nurs. 2020;26(1):5-9. https://doi.org/10.4069/kjwhn.2020. 03.11 .

2. Kim DH. Women's health during the COVID-19 pandemic. Korean J Women Health Nurs. 2020;26(2):106-108. https:// doi.org/10.4069/kjwhn.2020.06.10

3. Pinho-Gomes AC, Peters S, Thompson K, Hockham C, Ripullone K, Woodward M, et al. Where are the women? Gender inequalities in COVID-19 research authorship. BMJ Glob Health. 2020;5(7):e002922. https://doi.org/10.1136/bmjgh-2020-002922

4. Choi YS. Gendered characteristics of the employment crisis emerging from COVID-19 and the subsequent tasks. Issue Analysis; Nov 2020;170 (20-15) [Internet]. Suwon: Gyeonggido Women and Family Foundation; 2020 [cited 2020 Dec 17]. Available from: https://gfwri.kr/rnd/issue-analysis/?uid $=3608 \& \bmod =$ document

5. Ministry of Health and Welfare. Press report on the Gender Equality Policy Forum. May 28, 2020 [Internet]. Sejong: Author; 2020 [cited 2020 Dec 10]. Available from: http://ncov.mohw.go.kr/upload/viewer/skin/doc.html?fn=1590627429733_20200528095709. pdf\&rs =/upload/viewer/result/202012/

6. Drake EE. Celebrating year of the nurse and the midwife: time to tell your stories. Korean J Women Health Nurs. 2020;26(3):202-204. https://doi.org/10.4069/kjwhn.2020. 
05.14

7. Presidential Committee on Ageing Society and Population Policy. December 15, 2020 Press report: The fourth framework plans for 2021-2025. Seoul: Author; 2020 [cited 2020 Dec 19]. Available from: http://www.betterfuture.go.kr/front/notificationSpace/ pressReleaseDetail.do;jsessionid $=$ FE09791AA4EED078DDE-
86750C1EB157E.node10? articleId = 117

8. Chung Y, Kim S, Huh S. Influence of the COVID-19 pandemic on Asian scholarly journal editors' daily life, work, and opinions on future journal development. Sci Ed. 2020;7(2):111-117. https://doi.org/10.6087/kcse.204 